\title{
Exogenously applied glycinebetaine induced alteration in some key physio-biochemical attributes and plant anatomical features in water stressed oat (Avena sativa L.) plants
}

\author{
Anum SHEHZADI ${ }^{1}$, Nudrat A AKRAM ${ }^{1 *}$, Ayaz ALI ${ }^{1}$, Muhammad ASHRAF $^{2,3}$ \\ ${ }^{1}$ Department of Botany, Government College University, Faisalabad 38040, Pakistan; \\ ${ }^{2}$ Pakistan Science Foundation, Islamabad 44000, Pakistan; \\ ${ }^{3}$ Department of Botany, King Saud University, Riyadh 11564, Saudi Arabia
}

\begin{abstract}
Although exogenous application of glycinebetaine (GB) is widely reported to regulate a myriad of physio-biochemical attributes in plants under stressful environments including drought stress, there is little information available in the literature on how and up to what extent GB can induce changes in anatomical features in water starved plants. Thus, the present research work was conducted to assess the GB-induced changes in growth, physio-biochemical, and anatomical characteristics in two cultivars (CK-1 and F-411) of oat (Avena sativa L.) under limited water supply. After exposure to water stress, a considerable reduction was observed in plant growth in terms of lengths and weights of shoot and roots, leaf mesophyll thickness, leaf midrib thickness, root cortex thickness, root diameter, stem diameter, stem phloem area, and stem vascular bundle area in both oat cultivars. However, water stress resulted in a significant increase in leaf total phenolics, hydrogen peroxide $\left(\mathrm{H}_{2} \mathrm{O}_{2}\right)$, ascorbic acid (AsA), GB contents, activities of enzymes (CAT, SOD and POD), total soluble proteins, leaf epidermis (abaxial and adaxial) thickness, bulliform cell area, sclerenchyma thickness, root endodermis and epidermis thickness, root metaxylem area, stem metaxylem area and stem sclerenchyma thickness in both oat cultivars. Foliar-applied $100 \mathrm{mM} \mathrm{GB}$ suppressed $\mathrm{H}_{2} \mathrm{O}_{2}$ contents, while improved growth attributes, free proline and GB contents, activity of SOD enzyme, leaf abaxial epidermis thickness, leaf bulliform cell area, leaf midrib thickness, leaf sclerenchyma thickness, root cortex thickness, root endodermis, epidermis thickness, root stele diameter, stem diameter, stem epidermis thickness, stem metaxylem area, and stem phloem and vascular bundle area in both oat cultivars. For both oat cultivars, CK-1 was superior to F-411 in leaf abaxial epidermis thickness, leaf mesophyll, leaf sclerenchyma, root metaxylem area, stem diameter, stem epidermis, sclerenchyma thickness, stem metaxylem area, and stem vascular bundle area. Overall, both oat cultivars showed inconsistent behavior to water stress and foliar-applied GB in terms of different physio-biochemical attributes, however, CK-1 was superior to F-411 in a number of anatomical features of leaf, root, and stem.
\end{abstract}

Keywords: drought tolerance; anatomical features; oat; glycinebetaine; antioxidants

Citation: Anum SHEHZADI, Nudrat A AKRAM, Ayaz ALI, Muhammad ASHRAF. 2019. Exogenously applied glycinebetaine induced alteration in some key physio-biochemical attributes and plant anatomical features in water stressed oat (Avena sativa L.) plants. Journal of Arid Land, 11(2): 292-305. https://doi.org/10.1007/s40333-019-0007-8

\footnotetext{
*Corresponding author: Nudrat A AKRAM (E-mail: nudrataauaf@yahoo.com)

Received 2017-10-14; revised 2018-01-31; accepted 2018-07-06

(C) Xinjiang Institute of Ecology and Geography, Chinese Academy of Sciences, Science Press and Springer-Verlag GmbH Germany, part of Springer Nature 2019
} 


\section{Introduction}

Global environmental changes occurring currently at a fast pace are exacerbating stressful factors such as drought, salinity and extreme temperatures that are serious threats to global food security (Chaves and Oliveira, 2004; Ashikari and Feng-Ma, 2015) because almost all crops grown these days are prone to experience the drastic effects of such harsh environmental stresses, thereby resulting into low productivity (Ashraf, 2010). For example, drought stress is believed to adversely affect growth and development of all plant organs, and interrupt water use efficiency and stomatal conductance which make photosynthesis very sensitive to water stress (Seki et al., 2003; Ashraf and Harris, 2013). However, the detrimental effects of water stress depend on crop developmental stage and severity of the stress.

Plant cells experience various morphological, anatomical, physiological, and metabolic changes in response to drought stress, some of which have tolerance and adaptive significances that assist the plants to defend themselves against the stress (Cha-um and Kirdmanee, 2010; Nawaz and Ashraf, 2010). Moreover, these responses may cause the alteration in metabolic pathways leading to depletion or accumulation of metabolites such as organic compounds, hormones, carbohydrates, quaternary ammonium compounds, amino acids, and key enzymes (Chen and Murata, 2008; Rezaei et al., 2012). The organic compatible solutes such as glycinebetaine (GB), soluble sugars and proline can take part in the maintenance of cellular osmoregulation by regulating water relation components such as water, osmotic and turgor potentials (Khan et al., 2009; Hossain and Fujita, 2010).

Furthermore, these compatible solutes can also be used as markers of stress tolerance (Mahmood et al., 2009; Giri, 2011). It is believed that these compatible solutes protect the macromolecules and enzymes from oxidation by excessive reactive oxygen species (Ashraf and Foolad, 2007). Drought stress like other stresses can also affect anatomical structures of different organs, tissues and even cells analogous (Nemeskeri et al., 2010). For example, Nawaz et al. (2013) reported some drought-induced anatomical adaptations and modifications such as thick leaves and epidermis well developed bulliform cells, severe sclerification, smaller metaxylem vessels, increased leaf epidermal thickness, condensed and fibrous leaves, decreased stomatal area and density in blue panic (Panicum antidotale Retz.) ecotypes. It is believed that anatomical modifications such as reduced vessel size, mesophyll, and cortical parenchyma formation are essential to survive under water deficit conditions (Boughalleb et al., 2014).

It is evident that the synthesis of GB in plants is significantly lower than the level necessary for plant defense against stressful environments (Subbarao et al., 2001). Thus, the plants with an ability to produce low amount of GB require external application of GB to resist water stress. For example, foliar application of GB showed a beneficial effect on yield production and development of different crops, particularly in those crops that are deficit in amount of GB under water deficit conditions (Cha-um and Kirdmanee, 2010; Shahbaz et al., 2011). Shahbaz et al. (2011) have found that with foliar-applied of GB, yield production could be enhanced from $10 \%$ to $50 \%$ in wheat crop even under mild field water deficit conditions, while the effectiveness of GB application depends on the developmental stage of plant, number of applications, dose, stress conditions and the type of species (Ashraf et al., 2008).

As an important cereal and fodder crop, oat (Avena sativa L.) is grown all over the world. The productivity of this crop hampers under water deficit conditions (Iqbal et al., 2009). Keeping in view of these facts, we undertook a research study to examine that up to what extent drought stress can affect key physio-biochemical attributes and anatomical features of different plant organs. Moreover, it was also assessed whether exogenous application of GB could alleviate the adverse effects of water stress on the anatomical and physiological attributes of oat plants.

\section{Materials and methods}

Two oat cultivars F-411 and CK-1 were randomly selected for this experiment. A pot experiment with four replicates arranged in a completely randomized design was carried out in the Botanic Garden, Government College University, Faisalabad, Pakistan under natural environmental 
conditions. The seeds of selected cultivars were sown in 32 plastic pots $(2$ cultivars, 2 drought levels, 2 GB levels, and 4 replicates $)$ of uniform size $(30 \mathrm{~cm}$ in diameter and $24 \mathrm{~cm}$ deep $)$ at a rate of 8 seeds/pot and all pots filled with soil $(8 \mathrm{~kg}$; sandy-loam). Thinning of the plants was carried-out after sprouting of the seeds as uniform five plants per pot were maintained. The average ambient temperature varied between $10^{\circ} \mathrm{C}$ and $24^{\circ} \mathrm{C}$ during the growing season and soil moisture contents maintained on daily basis. Two levels of water stress (control $(100 \%$ field capacity) and drought (60\% field capacity)) were initiated after 15 days of seed germination. After 30 days of water stress treatments, GB at the concentration of $100 \mathrm{mM}$ including $0.1 \%$ Tween-20 applied as a foliar spray once with $20 \mathrm{~mL}$ per plant by using a hand-sprayer pump. After 15 days of GB application as a foliar spray, the data were collected for the following attributes.

\subsection{Growth attributes}

Two plants per replicate that having the heights of 14-16 cm (control) and 8-10 cm (drought) were harvested and washed with distilled water and recorded the shoot and root dry weights.

\subsection{Anatomical features}

At the same time, leaf, stem and root samples for anatomical studies were collected from two plants. All plant samples were processed in formalin-acid-alcohol (FAA) solution, which was prepared by taking distilled water $(525 \mathrm{~mL})$, acetic acid $(75 \mathrm{~mL})$, formaldehyde $(150 \mathrm{~mL})$ and ethyl alcohol $(750 \mathrm{~mL})$. An aliquot of $30 \mathrm{~mL}$ of the FAA solution was taken from the stock solution and added to each bottle. Flag leaves, stems and roots were taken $(2-3 \mathrm{~cm})$ from each treatment, washed well in distilled water and preserved them in the FAA solution. The plant samples were then fixed in acetic alcohol solution for $24 \mathrm{~h}$ at the room temperature. The sections of all samples were free-hand cut following Ruzin (1999). After completing the staining procedure, the sections were shifted on slides, added one drop of Canada balsam on each of the sections, and covered the section with a cover slip. The permanent slides were preserved for taking micrographs. Finally, measurements of the micrographs were done using a light microscope (MEIJI Techno, ML2100, Japan). During the study, data for anatomical features of leaf, stem, and root (thickness, size of parenchymatous cells, dermal, mechanical, and conducting tissues) were recorded.

\subsection{Physio-biochemical characteristics}

Leaf samples were collected and preserved in an ultra-low freezer for the determination of physio-biochemical parameters.

\subsection{Chlorophyll content}

Following Arnon (1949), $0.5 \mathrm{~g}$ fresh leaf was extracted in $80 \%$ acetone $(10 \mathrm{~mL} ; \mathrm{v} / \mathrm{v})$ and the supernatant was used for the determination of chlorophyll $a$ and $b$ contents.

\subsection{Ascorbic acid (AsA)}

Each leaf sample $(0.25 \mathrm{~g})$ was extracted with $10 \mathrm{~mL}$ of $6 \%(\mathrm{w} / \mathrm{v}) \mathrm{TCA}$. AsA contents were determined following Mukherjee and Choudhuri (1983).

\subsection{Total phenolics}

The method of Julkunen-Titto (1985) was used to determine total phenolics in leaf tissues.

\subsection{Hydrogen peroxide $\left(\mathrm{H}_{2} \mathrm{O}_{2}\right)$}

In a pre-chilled pestle and mortar, fresh leaf material $(0.5 \mathrm{~g})$ was homogenized in $5 \mathrm{~mL}$ of $0.1 \%$ (w/v) trichloro-acetic acid (TCA) and $\mathrm{H}_{2} \mathrm{O}_{2}$ concentration was determined following Velikova et al. (2000).

\subsection{Malondialdehyde (MDA)}

Fresh leaf material $(0.5 \mathrm{~g})$ was homogenized in $5 \mathrm{~mL}$ of $5 \%(\mathrm{w} / \mathrm{v}) \mathrm{TCA}$, and then it was centrifuged at $12,000 \mathrm{~g}$ for $15 \mathrm{~min}$. The remaining procedure was adopted as proposed by Cakmak and Horst (1991). 


\subsection{Free proline content}

According to the method of Bates et al. (1973), we prepared the samples and recorded the optical density of the mixture at $520 \mathrm{~nm}$ using a UV-visible spectrophotometer.

\subsection{Glycinebetaine (GB)}

The dry leaf sample $(0.5 \mathrm{~g})$ was ground in $10 \mathrm{~mL}$ of $0.5 \%$ toluene solution and the extract was kept overnight at $4^{\circ} \mathrm{C}$. Then, the remaining procedure proposed by Grieve and Grattan (1983), was followed, and absorbance was recorded at $365 \mathrm{~nm}$.

\subsection{Enzymatic antioxidants}

Fresh leaves $(0.5 \mathrm{~g})$ were extracted in $5 \mathrm{~mL}$ phosphate buffer $(50 \mathrm{mM})$ of $\mathrm{pH} 7.8$. After centrifugation at $15,000 \mathrm{~g}$ for $20 \mathrm{~min}$ at $4^{\circ} \mathrm{C}$, the supernatant was used for determining the activities of the antioxidant enzymes, i.e., peroxidase (POD) and catalase (CAT), following Chance and Maehley (1955) along with superoxide dismutase (SOD) following Giannopolitis and Ries (1977). We recorded the enzyme activities on the basis of total soluble proteins estimated following Bradford (1976).

\subsection{Statistical analysis}

The collected data for all attributes were subjected to analysis of variance technique (ANOVA) using Co-Stat version 6.2 (Monterey, CA, USA). The least significance difference was calculated following Snedecor and Cochran (1980).

\section{Results}

Shoot and root dry weights were significantly suppressed due to water deficiency $(P \leq 0.001$; Figs. $1 \mathrm{a}$ and b). Foliar-applied GB at the concentration of $100 \mathrm{mM}$ considerably improved growth attributes of both oat cultivars particularly the shoot and root dry weights under water stress as well as non-stress conditions. The response of both oat cultivars was similar to water stress as well as foliar-applied GB. Meanwhile, a significant decline was observed in shoot and root lengths of both oat cultivars under water deficit conditions $(P \leq 0.001$; Figs. 1c and d). Shoot length was observed to be improved significantly both in water stressed and non-stressed plants of both cultivars due to foliar application of GB, however, no change was observed in root length. Both cultivars were similar in shoot and root lengths.

An increase in leaf total phenolics was observed in both oat cultivars due to water stress $(P \leq 0.05$; Fig. 1e). A similar response of both oat cultivars in total phenolics was observed to drought stress and foliar-applied GB applications. Leaf free proline contents remained unchanged in both oat cultivars under water deficit conditions. However, exogenous application of GB increased the proline contents in both oat cultivars particularly under water deficit conditions (Fig. 1f). Both cultivars showed a similar response in terms of proline accumulation under both water regimes. No change in malondialdehyde (MDA) contents was observed due to water stress as well as foliar-applied GB. Similarly, no change was observed in the response of both oat cultivars to MDA accumulation (Fig. 1g). A significant increase in hydrogen peroxide $\left(\mathrm{H}_{2} \mathrm{O}_{2}\right)$ contents was observed in both oat cultivars under water deficit conditions $(P \leq 0.001$; Fig. 1h). Foliar-applied GB considerably suppressed the $\mathrm{H}_{2} \mathrm{O}_{2}$ contents in both oat cultivars under water limited conditions. Almost a similar response was observed in both oat cultivars in terms of $\mathrm{H}_{2} \mathrm{O}_{2}$ accumulation under water deficit conditions.

Chlorophyll $a$ and $b$ contents were not affected under water deficit conditions as well as foliar-applied GB. There was no significant difference between the two oat cultivars in chlorophyll contents (Figs. 2a and b). Ascorbic acid (AsA) contents significantly increased under drought stress conditions but exogenous application of GB had no effect on AsA contents in both oat cultivars $(P \leq 0.01$; Fig. $2 \mathrm{c})$. Of both oat cultivars, F-411 was relatively higher in AsA contents than CK-1 particularly under water deficit conditions. Accumulation of GB contents increased due to imposition of water deficit conditions as well as foliar-applied GB at the concentration of 

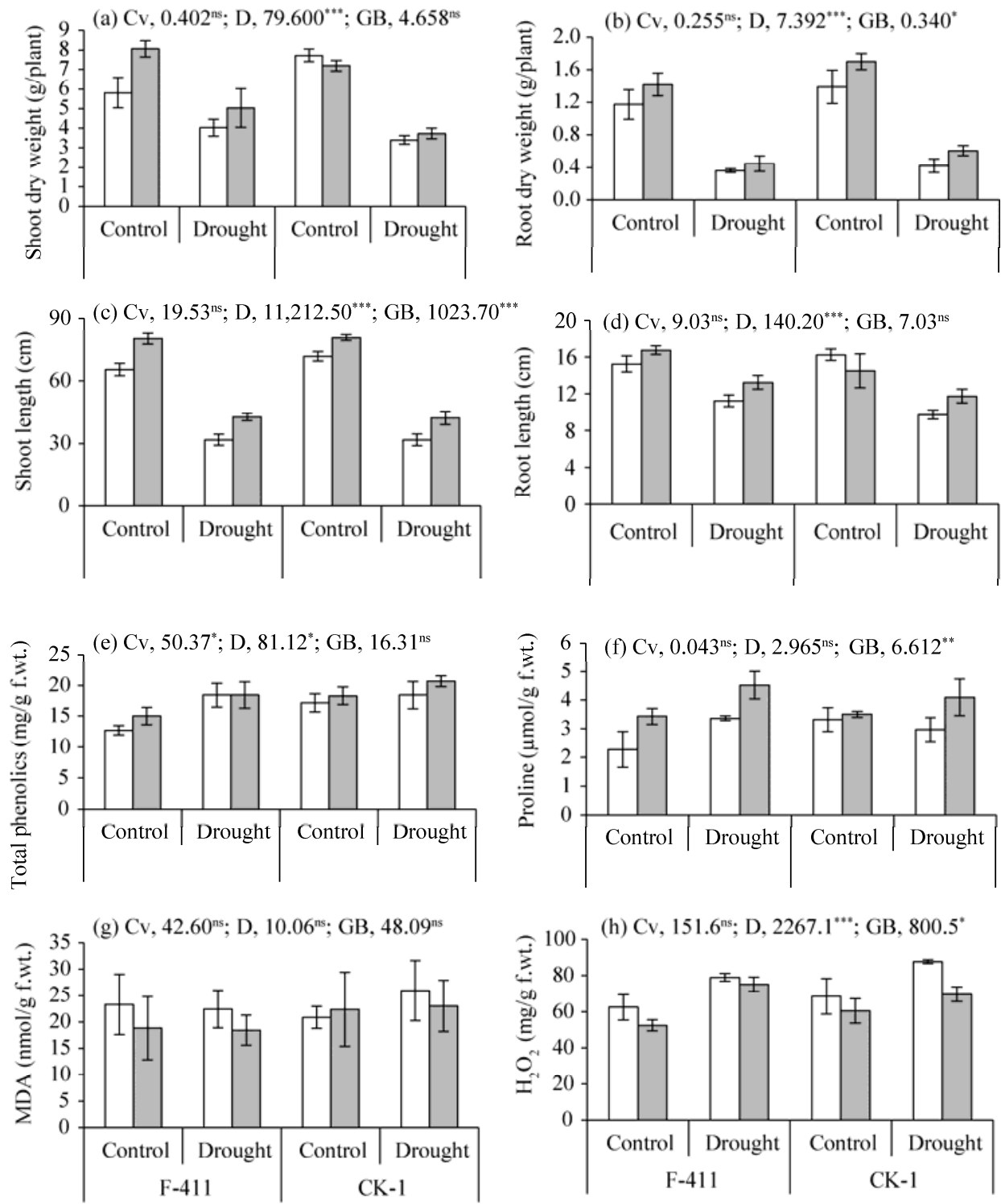

Non-GB treatment

$100 \mathrm{mM}$ GB application

Fig. 1 Shoot (a) and root dry weights (b), shoot (c) and root lengths (d), total phenolics (e), proline (f), malondialdehyde (MDA, g), and hydrogen peroxide $\left(\mathrm{H}_{2} \mathrm{O}_{2}\right)$ contents (h) of oat (Avena sativa L.) plants foliar-treated with glycinebetaine $(\mathrm{GB})$ at vegetative stage under varying water regimes. ${ }^{*},{ }^{* *}$, and ${ }^{* * *}$ indicate significances at the $0.05,0.01$ and 0.001 levels, respectively; ${ }^{\text {ns }}$, non-significant; $\mathrm{Cv}$, Cultivars; D, Drought. The significance value was shown for each treatment; f.wt., fresh weight.

$100 \mathrm{mM}$. No significant difference was observed between the two oat cultivars in GB accumulation.

The activities of antioxidant enzymes such as catalase (CAT), peroxidase (POD), and superoxide dismutase enzymes (SOD) increased significantly in both oat cultivars by exposure to drought stress $(P \leq 0.001$; Figs. $2 \mathrm{e}-\mathrm{g})$. However, foliar application of GB was effective only in enhancing the activity of SOD enzyme in both oat cultivars under both watering regimes. Of both cultivars, F-411 was relatively higher in CAT activity than CK-1, while in case of other enzymes there was no significant difference between the two cultivars. Drought stress significantly improved the total soluble proteins of both oat cultivars particularly under water deficit conditions $(P \leq 0.001$; Fig. 2 h). No effect of GB application was observed on total soluble proteins. Both oat 

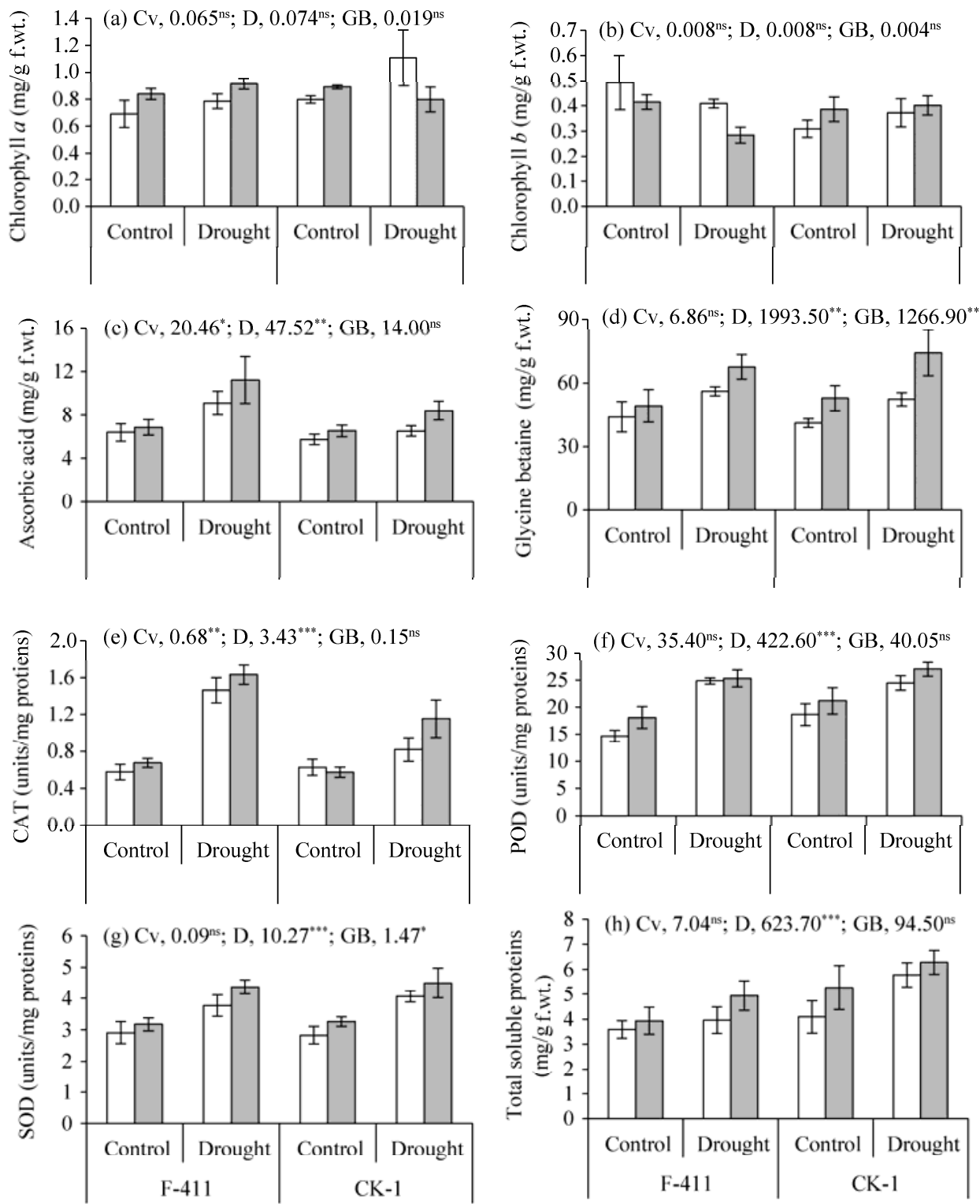

$\square$ Non-GB treatment

$100 \mathrm{mM}$ GB application

Fig. 2 Chlorophyll $a(\mathrm{a})$ and $b$ (b), ascorbic acid (c), glycine betaine contents (d), activities of catalase (CAT, e), peroxidase (POD, f), and superoxide dismutase enzymes (SOD, g) and total soluble proteins (h) of oat (Avena sativa L.) plants foliar-treated with glycinebetaine $(\mathrm{GB})$ at vegetative stage under varying water regimes. ${ }^{*},{ }^{* *}$, and ${ }^{* * *}$ indicate significances at the $0.05,0.01$ and 0.001 levels, respectively; ${ }^{n}$, non-significant; $\mathrm{Cv}, \mathrm{Cultivars}$; D, Drought. The significance value was shown for each treatment; f.wt., fresh weight.

cultivars were similar in total soluble proteins under water deficit conditions as well as GB treatments.

Leaf epidermis (abaxial and adaxial) thickness was found to be considerably increased in both oat cultivars under water deficit conditions (Figs. 3a and b). Exogenously applied GB was effective in improving only the leaf abaxial epidermis thickness. Of both oat cultivars, CK-1 was relatively superior to F-411 in leaf abaxial epidermis thickness, while leaf adaxial epidermis thickness was similar in both oat cultivars under varying water regimes. However, no change was observed in leaf blade thickness and leaf metaxylem area due to imposition of water stress as well as foliar-applied GB (Figs. 3c and f). Of both oat cultivars, CK-1 was relatively better than F-411 
in leaf blade thickness, while leaf metaxylem area was similar in both oat cultivars under varying water regimes.

Leaf bulliform cell area considerably increased in both oat cultivar due to water deficit conditions and foliar-applied GB (Fig. 3d). The response of both oat cultivars was similar to water stress and exogenously applied GB. Leaf mesophyll thickness decreased in F-411, while no change was observed in CK-1 under water limited conditions (Fig. 3e). Exogenously applied GB was ineffective in altering the leaf mesophyll thickness in both oat cultivars. Of both oat cultivars, CK-1 was relatively better than F-411 in leaf mesophyll thickness under both water regimes.
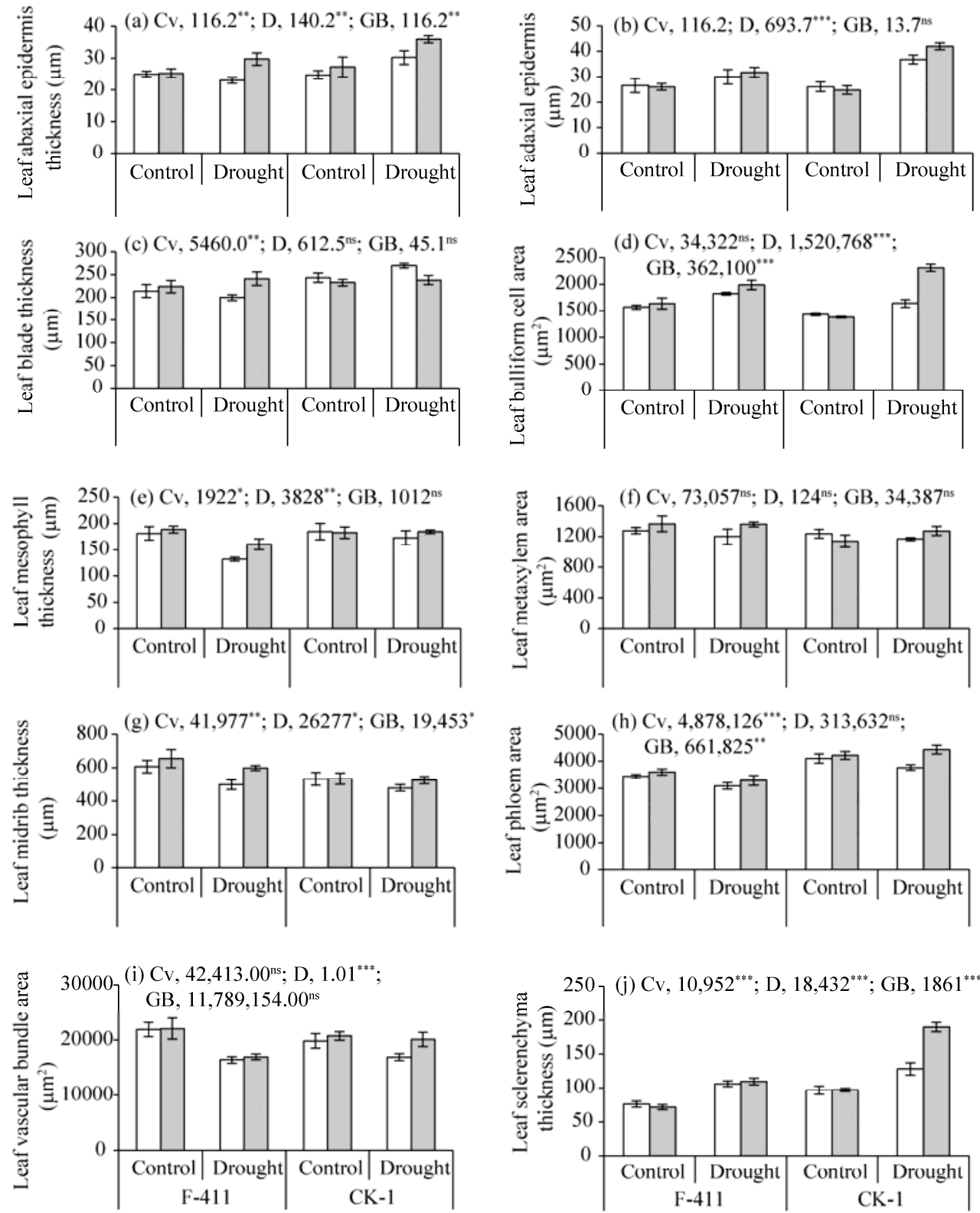

$\square$ Non-GB treatment

$100 \mathrm{mM} \mathrm{GB}$ application

Fig. 3 Leaf abaxial epidermis (a), adaxial epidermis (b), blade thickness (c), bulliform cell area (d), mesophyll thickness (e), metaxylem area (f), midrib thickness (g), phloem area (h), vascular bundle area (i) and sclerenchyma thickness (j) of oat (Avena sativa L.) plants foliar-treated with glycinebetaine (GB) grown under varying water regimes. ${ }^{*},{ }^{* *}$, and ${ }^{* * *}$ indicate significances at the $0.05,0.01$ and 0.001 levels, respectively; ${ }^{\text {ns }}$, non-significant; Cv, Cultivars; D, Drought. The significance value was shown for each treatment. 
Meanwhile, a significant decrease in leaf midrib thickness was observed in both oat cultivars at $60 \%$ field capacity $(P \leq 0.05$; Fig. $3 \mathrm{~g})$. However, foliar-applied GB significantly improved the leaf midrib thickness in both two cultivars subjected to water stress conditions. The response of both cultivars was significantly different, and CK-1 was inferior to F-411 in leaf midrib thickness particularly under drought stress conditions.

Drought stress (60\% field capacity) significantly improved the leaf sclerenchyma thickness $(P \leq 0.001$; Fig. 3j). However, foliar-applied GB further improved this anatomical feature in both two oat cultivars subjected to water stress conditions. Furthermore, of both oat cultivars, CK-1 was superior to F-411 in leaf sclerenchyma thickness under drought stress conditions.

The root cortex thickness and root diameter in both oat cultivars significantly decreased $(P \leq 0.001$; Figs. $4 \mathrm{a}$ and $\mathrm{b})$. However, foliar-applied GB significantly improved only root cortex thickness in both oat cultivars subjected to water stress as well as non-stress conditions. Drought stress significantly increased the root endodermis and epidermis thickness of both oat cultivars $(P \leq 0.001$; Figs. $4 \mathrm{c}$ and $\mathrm{d})$. Foliar-applied GB significantly improved $(P \leq 0.01)$ the root endodermis and epidermis thickness in both oat cultivars subjected to water stress as well as non-stress conditions. No significant difference between the two cultivars was observed in root endodermis and epidermis thickness under varying water regimes. Meanwhile, drought stress significantly increased the root metaxylem area, while no change was observed in root stele
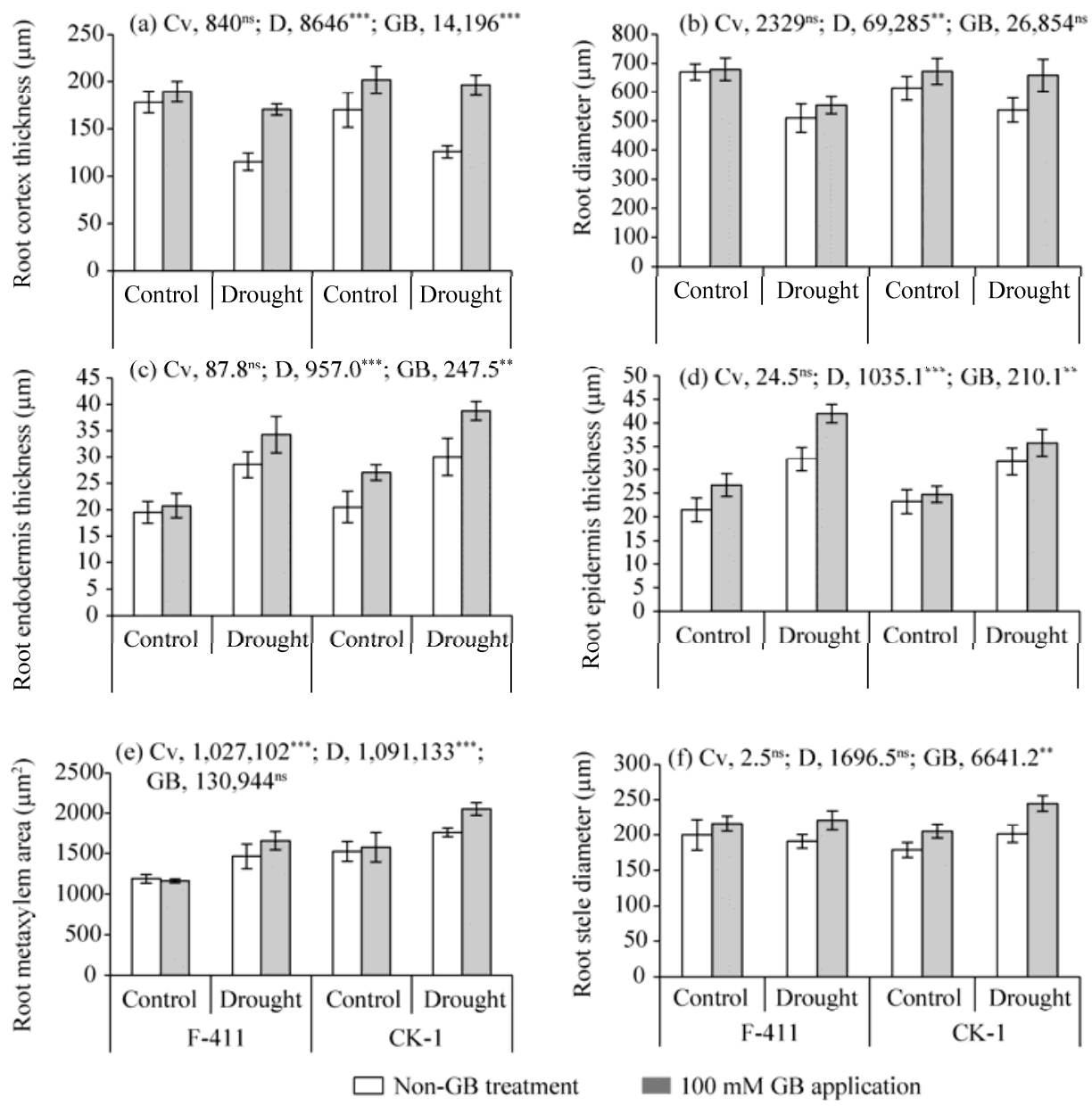

Fig. 4 Root cortex thickness (a), diameter (b), endodermis thickness (c), epidermis thickness (d), metaxylem area (e), and stele diameter (f) of oat (Avena sativa L.) plants foliar-treated with glycinebetaine (GB) at vegetative stage under varying water regimes. ${ }^{* *}$ and ${ }^{* * *}$ indicate significances at the $0.05,0.01$ and 0.001 levels, respectively; ns, non-significant; Cv, Cultivars; D, Drought. The significance value was shown for each treatment. 
diameter in both two cultivars $(P \leq 0.001$; Figs. $4 \mathrm{e}$ and $\mathrm{f})$. Foliar-applied GB did not change the root metaxylem area, while an increase in root stele diameter in both oat cultivars was observed after exposure to water stress conditions. Of both oat cultivars, CK-1 was better than F-411 in root metaxylem area under drought stress conditions.

Drought stress significantly decreased the stem diameter, while no change was observed in stem epidermis thickness due to water stress conditions in both cultivars $(P \leq 0.001$; Figs. 5a and b). However, foliar-applied GB significantly improved $(P \leq 0.001)$ both the anatomical features in both oat cultivars subjected to water stress as well as non-stress conditions. The response of both oat cultivars was significantly different, i.e., CK-1 showed better results of both anatomical features as compared to F-411 after exposure to water stress and GB applications.
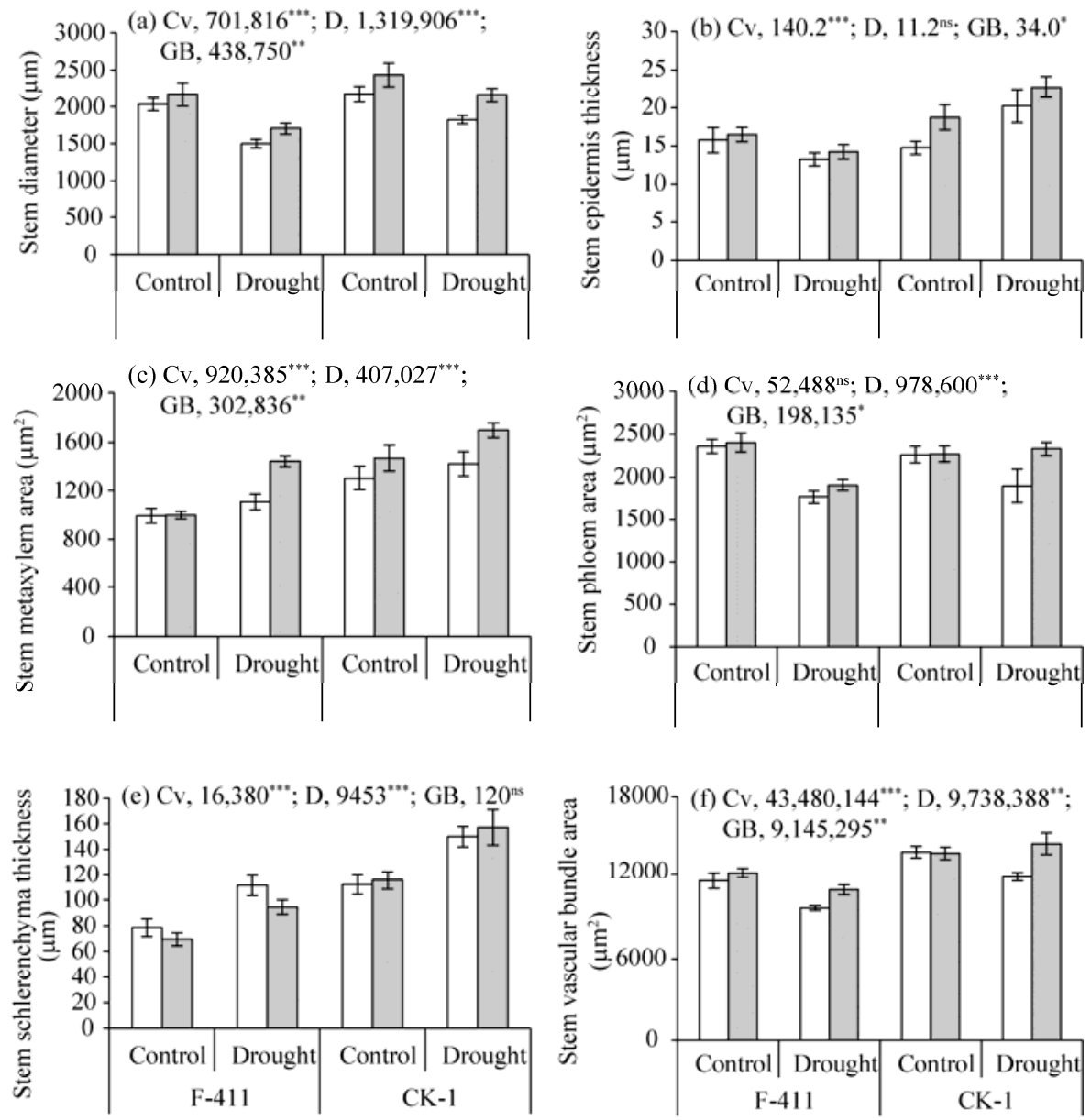

$\square$ Non-GB treatment

100 mM GB application

Fig. 5 Stem diameter (a), epidermis thickness, metaxylem area, phloem area, stem sclerenchyma thickness and vascular bundle area of oat (Avena sativa L.) foliar-treated with glycinebetaine (GB) at vegetative stage under varying water regimes. ${ }^{*},{ }^{* *}$, and ${ }^{* * *}$ indicate significances at the $0.05,0.01$ and 0.001 levels, respectively; ${ }^{\text {ns }}$, non-significant; Cv, Cultivars; D, Drought. The significance value was shown for each treatment.

Stem metaxylem area and sclerenchyma thickness significantly increased in both oat cultivars under drought conditions ( $P \leq 0.001$; Figs. $5 \mathrm{c}$ and e). However, foliar-applied GB improved only the stem metaxylem area in both oat cultivars subjected to water stress as well as non-stress conditions (Figs. 5d). Of both oat cultivars, CK-1 was superior to F-411 in stem metaxylem area and sclerenchyma thickness under different water regimes. Meanwhile, a significant decrease in stem phloem area was observed in both oat cultivars due to drought stress. However, foliar-applied GB significantly improved the stem phloem area in both oat cultivars subjected to 
both water regimes. The response of both oat cultivars in stem phloem area was similar to drought stress conditions (Fig. 5d). Similarly, water stress caused a significant reduction in stem vascular bundle area in both oat cultivars (Fig. 5f). However, foliar-applied GB significantly improved the stem vascular bundle area in both oat cultivars subjected to water stress as well as non-stress conditions. Of both oat cultivars, CK-1 showed a better response in stem vascular bundle area than F-411 to drought stress and GB applications.

\section{Discussion and conclusions}

Drought stress is one of the major causes for crop yield loss worldwide especially in arid and semi-arid regions. This dynamic stress is projected to reduce average yields of major crops by more than 50\% (Wang et al., 2003). However, it is well reported that plants modulate their physio-biochemical processes and anatomical features according to the internal or external climate so as to survive under such harsh conditions (Shafiq et al., 2015; Akram et al., 2016). In the present study, plant growth measured as shoot and root dry weights of both oat cultivars decreased under water deficit conditions, which is in agreement with some earlier findings which also reported a water stress-induced decline in growth of various crops such as wheat (Jatoi et al., 2011; Raza et al., 2012), mungbean (Sadiq et al., 2017), sugar beet (Bloch et al., 2006), grasses (Akram et al., 2007), maize (Zhang et al., 2012) and radish (Akram et al., 2015). They found that water stress-reduced plant growth is linked to the interior status of the plant with respect to specifically photosynthesis, nutrients, hormones, antioxidants, primary and secondary metabolites, fluorescence, quantum use efficiency, respiration, and photosynthetic pigments, etc. (Ashraf and Harris, 2013; Sadiq et al., 2017).

It is found that exogenous application of different compatible organic solutes is one of the most prospective shotgun means for improving plants stress tolerance (Ashraf and Foolad, 2007; Ahmad et al., 2016). It is well noted that exogenous application of GB can effectively regulate some key physio-biochemical attributes in plants under stress conditions and alleviate the adverse effects of water stress, however, the response of different plants was found to be a species or cultivar specific (Mahmood et al., 2009; Akram et al., 2016). For example, exogenously applied GB showed a beneficial effect on the growth of different plants under drought stress, e.g., sunflower (Hussain et al., 2008), rice (Farooq et al., 2008), wheat (Ma et al., 2006), and tobacco (Ma et al., 2007).

Leaf free proline and total phenolics contents have been reported to increase under water deficit regimes in different plant species, e.g., cotton (Ahmed et al., 2011), wheat (Hameed et al., 2013), cowpea (Hamidou et al., 2007), chickpea (Mafakheri et al., 2010), soybean (Mwenye et al., 2016), and rice (Lum al., 2014). Similarly, leaf total phenolics increased in both oat cultivars under drought stress conditions as well as foliar application of GB in this study. While, a contrasting pattern has been observed in the case of proline content in the present study, e.g., free proline contents remained unchanged in both oat cultivars due to water deficit conditions; however, exogenously applied GB enhanced the leaf proline contents in both cultivars under drought stress.

Usually, accumulation of proline within cells/tissues not only depends on the type or intensity of a stress, but also on the levels of endogenous primary and secondary metabolites, as well as type of a plant species to be investigated (Ashraf et al., 2011). It is widely reported that endogenous levels of proline and total phenolics are the indicators of a stress and can be used as selection criteria for stress tolerance (Akram et al., 2016; Sadiq et al., 2017).

Similarly, levels/activities of antioxidants (non-enzymatic/enzymatic) can be used as the vital selection criteria for stress tolerance. In the present study, ascorbic acid, one of the potential non-enzymatic antioxidants, markedly increased in both oat cultivars under drought stress conditions, although externally applied GB had no significant effect on ascorbic acid content. Similar to our study, previously an increase in ascorbic acid content was found in tomato plants exposed to low water stress in two different studies (Behnamnia et al., 2009; Ghorbanli et al., 2013). The enzymatic antioxidants were found to be also increased in both oat cultivars in the present investigation, which is parallel to what had been earlier observed in different 
cultivars/lines of rice (Lum et al., 2014), black gram (Pratap and Sharma, 2010), pigeon pea (Kumar et al., 2011), and wheat (Hasheminasab et al., 2012; Omar, 2012). Interestingly, foliar-applied GB significantly enhanced the activity of SOD enzyme more than those of CAT and POD in both oat cultivars under different water regimes. So, the GB-induced growth improvement in both oat cultivars could be linked to elevated activities of these key antioxidant enzymes.

In the present study, in addition to regulating some key physio-biochemical attributes, exogenous use of GB was found to be effective in up-regulating some anatomical features which are directly or indirectly involved in water stress tolerance of oat plants. In view of some earlier studies, considerable anatomical changes in different plants have been observed under water limited environments (Makbul et al., 2011). However, not a single study has been carried out so far to assess the effect of exogenously applied osmoprotectants including GB in altering the leaf, stem, or root anatomy of plants. In a previous study, Ozorgucu et al. (1991) demonstrated that the anatomical features were influenced by environmental conditions. The anatomical features undergo significant changes particularly under stress conditions (Makbul et al., 2006; Makbul et al., 2008). For example, Aldesuquy et al. (2013) found that water stress caused considerable decreases in leaf thickness, ground tissue thickness, metaxylem vessel area, xylem vessel area, phloem tissue area, vascular bundle area in wheat plants. However, in the present study, drought stress caused significant decreases in leaf vascular bundle area, midrib thickness, blade thickness, and mesophyll thickness in both oat cultivars (F-411 and CK-1). Furthermore, the application of GB was proved to be ineffective in altering leaf blade and leaf mesophyll thickness, while, the leaf midrib thickness of the GB-treated plants increased under water stress conditions. Balsamo et al. (2006) reported that increased epidermis thickness and development of bulliform cells are directly linked to drought tolerance in most plants. Similar results were observed in the present study that drought stress increased leaf bulliform cell area and abaxial epidermis thickness by the exogenously applied GB in both oat cultivars. In view of an earlier report, increase in leaf thickness under drought stress could be due to parenchymatous cells, which are the most important storing cells of leaf, and therefore, are chiefly important under water deficit environments (Abdel and Al-Rawi, 2011).

The most promising anatomical features associated with drought resistance include the increases in metaxylem area, exodermis thickness, and severe sclerification in vascular region (Nawaz et al., 2013). Recently, Saeed et al. (2016) examined some anatomical changes in the roots of chickpea (Cicer arietinum L.) under drought stress conditions. They found that root length and number of secondary roots decreased, while number of medullary rays and vascular region increased under water deficit conditions. Boughalleb et al. (2014) found that anatomical variations such as reduced vessel size, mesophyll thickness, and cortical parenchyma development were observed in Astragalus gombiformis under water stress conditions for the maintenance of energy storage and improved resistance for survival of the plants in dry areas. Vasellati et al. (2001) reported that under water deficit conditions, diameter of root and metaxylem area decreased in Paspalum dilatatum, thereby lowering the risk of embolism, increasing the water-flow resistance and number of root hairs, which could increase the water uptake ability in the plant. While, in the present study, leaf abaxial epidermis thickness, leaf bulliform cell area, leaf midrib thickness, leaf sclerenchyma thickness, root cortex thickness, root endodermis, epidermis thickness, root stele diameter, stem diameter, stem epidermis thickness, stem metaxylem area, and stem phloem were improved by foliar-applied GB in both oat cultivars exposed to water deficit conditions, which proved that GB can modify some key anatomical features in plants like oat for making the plants resistant to harsh environmental conditions.

In conclusion, foliar-applied $\mathrm{GB}$ suppressed $\mathrm{H}_{2} \mathrm{O}_{2}$ contents, while improved growth attributes, free proline and GB contents, activity of SOD enzyme, leaf abaxial epidermis thickness, leaf bulliform cell area, leaf midrib thickness, leaf sclerenchyma thickness, root cortex thickness, root endodermis, epidermis thickness, root stele diameter, stem diameter, stem epidermis thickness, stem metaxylem area, and stem phloem and vascular bundle area in both oat cultivars. Of both oat cultivars, CK-1 was superior to F-411 in leaf abaxial epidermis thickness, leaf mesophyll, leaf sclerenchyma, root metaxylem area, stem diameter, stem epidermis and sclerenchyma thickness, 
stem metaxylem area, and stem vascular bundle area. Overall, the response of both oat cultivars was similar to water stress and foliar-applied GB in terms of different physio-biochemical attributes appraised; however, CK-1 was superior to F-411 in a number of anatomical features of leaf, root, and stem.

\section{Acknowledgments}

The research work presented in this manuscript was financially supported by the Department of Botany, Government College University, Faisalabad, Pakistan.

\section{References}

Abdel C G, Al-Rawi I M T. 2011. Anatomical alteration in response to irrigation and water stress in some legume crops. American Journal of Experimental Agriculture, 1(4): 231-264.

Ahmad P, Rasool S, Gul A, et al. 2016. Jasmonates: Multifunctional roles in stress tolerance. Frontiers in Plant Science, $7: 813$.

Ahmed M F E M, Mac D M, Bashir A A G. 2011. Effect of water stress at different periods on seed yield and water use efficiency of guar under Shambat conditions. Agricultural Sciences, 2(3): 262-266.

Akram N A, Shahbaz M, Ashraf M. 2007. Relationship of photosynthetic capacity and proline accumulation with the growth of differently adapted populations of two potential grasses (Cynodon dactylon (L.) Pers. and Cenchrus ciliaris L.) to drought stress. Pakistan Journal of Botany, 39(3): 777-786.

Akram N A, Noreen S, Noreen T, et al. 2015. Exogenous application of trehalose alters growth, physiology and nutrient composition in radish (Raphanus sativus L.) plants under water deficit conditions. Brazilian Journal of Botany, 38(3): 431-439.

Akram N A, Shafiq S, Ashraf M, et al. 2016. Drought-induced anatomical changes in radish (Raphanus sativus L.) leaves supplied with trehalose through different modes. Arid Land Research and Management, 30(4): 412-420.

Aldesuquy H S, Abbas M A, Abo-Hamed S A, et al. 2013. Does glycine betaine and salicylic acid ameliorate the negative effect of drought on wheat by regulating osmotic adjustment through solutes accumulation? Journal of Stress Physiology and Biochemistry, 9(3): 5-22.

Arnon D I. 1949. Copper enzymes in isolated chloroplast, polyphenoloxidase in Beta vulgaris L. Journal of Plant Physiology, 24(1): 1-15.

Ashikari M, Feng-Ma J. 2015. Exploring the power of plants to overcome environmental stresses. Rice (NY), 8: 10.

Ashraf M, Foolad M R. 2007. Roles of glycine betaine and proline in improving plant abiotic stress resistance. Environmental and Experimental Botany, 59(2): 206-216.

Ashraf M, Athar H R, Harris P J C, et al. 2008. Some prospective strategies for improving crop salt tolerance. Advances in Agronomy, 97: 45-110.

Ashraf M. 2010. Inducing drought tolerance in plants: recent advances. Biotechnology Advances, 28(1): 169-183.

Ashraf M, Akram N A, Al-Qurainy F, et al. 2011. Drought tolerance: Roles of organic osmolytes, growth regulators, and mineral nutrients. Advances in Agronomy, 111: 249-296.

Ashraf M, Harris P J C. 2013. Photosynthesis under stressful environments: An overview. Photosynthetica, 51(2): $163-190$.

Balsamo R A, Willigen C V, Baue A M, et al. 2006. Drought tolerance of selected Eragrostis species correlates with leaf tensile properties. Annals of Botany, 97(6): 985-991.

Bates L S, Waldren R P, Teare I D. 1973. Rapid determination of free proline for water stress studies. Plant and Soil, 39(1): 205-207.

Behnamnia M, Kalantari K M, Rezanejad F. 2009. Exogenous application of brassinosteroid alleviates drought-induced oxidative stress in Lycopersicon esculentum L. General and Applied Plant Physiology, 35(1-2): 22-34.

Bloch D, Hoffmann C M, Märander B. 2006. Impact of water supply on photosynthesis, water use and carbon isotope discrimination of sugar beet genotypes. European Journal of Agronomy, 24(3): 218-225.

Boughalleb F, Abdellaoui R, Brahim N, et al. 2014. Anatomical adaptations of Astragalus gombiformis Pomel. under drought stress. Central European Journal of Biology, 9(12): 1215-1225.

Bradford M M. 1976. A rapid and sensitive method for the quantitation of microgram quantities of protein utilizing the principle of protein-dye binding. Annual Biochemistry, 72(1-2): 248-254.

Carmak I, Horst W J. 1991. Effects of aluminum on lipid peroxidation, superoxide dismutase, catalase, and peroxidase activities in root tips of soybean (Glycine max). Physiologia Plantarum, 83(3): 463-468.

Chance B, Maehly A C. 1955. Assay of catalases and peroxidases. Methods in Enzymology, 2: 764-775.

Cha-um S, Kirdmanee C. 2010. Effect of glycinebetaine on proline, water use, and photosynthetic efficiencies, and growth of rice 
seedlings under salt stress. Turkish Journal of Agriculture and Forestry, 34: 517-527.

Chaves M M, Oliveira M M. 2004. Mechanisms underlying plant resilience to water deficits: Prospects for water-saving agriculture. Journal of Experimental Botany, 55(407): 2365-2384.

Chen T H H, Murata N. 2008. Glycinebetaine: an effective protectant against abiotic stress in plants. Trends in Plant Science, 13(9): 499-505.

Farooq M, Basra S M A, Wahid A, et al. 2008. Physiological role of exogenously applied glycinebetaine to improve drought tolerance in fine grain aromatic rice (Oryza sativa L.). Journal of Agronomy and Crop Sciences, 194(5): 325-333.

Ghorbanli M, Gafarabad M, Amirkian T, et al. 2013. Investigation of proline, total protein, chlorophyll, ascorbate and dehydroascorbate changes under drought stress in Akria and Mobil tomato cultivars. Iranian Journal of Plant Physiology, 3(2): 651-658.

Giannopolitis C N, Ries S K. 1977. Superoxide dismutase. I. Occurrence in higher plants. Plant Physiology, 59(2): 309-314.

Giri J. 2011. Glycinebetaine and biotic stress tolerance in plants. Plant Signaling \& Behavior, 6(11): 1746-1751.

Grieve C M, Grattan S R. 1983. Rapid assay for determination of water soluble quaternary ammonium compounds. Plant and Soil, 70(2): 303-307.

Hameed A, Goher M, Iqbal N. 2013. Drought induced programmed cell death and associated changes in antioxidants, proteases, and lipid peroxidation in wheat leaves. Biologia Plantarum, 57(2): 370-374.

Hamidou F, Zombre G, Diouf O, et al. 2007. Physiological, biochemical and agro-morphological responses of five cowpea genotypes (Vigna unguiculata (L.) Walp.) to water deficit under glasshouse conditions. Biotechnology, Agronomie, Societie and Environment, 11(3): 225-234.

Hasheminasab H, Assad M T, Aliakbari A, et al. 2012. Influence of drought stress on oxidative damage and antioxidant defense systems in tolerant and susceptible wheat genotypes. Journal of Agricultural Science, 4(8): 20-30.

Hossain M A, Fujita M. 2010. Evidence for a role of exogenous glycinebetaine and proline in antioxidant defense and methylglyoxal detoxification systems in mung bean seedlings under salt stress. Physiology and Molecular Biology of Plants, 16(1): 19-29.

Hussain M, Malik M A, Farooq M, et al. 2008. Improving drought tolerance by exogenous application of glycinebetaine and salicylic acid in sunflower. Journal of Agronomy and Crop Science 194(3): 193-199.

Iqbal N, Ashraf M, Ashraf M Y. 2009. Influence of exogenous glycine betaine on gas exchange and biomass production in sunflower (Helianthus annuus L.) under water limited conditions. Journal of Agronomy and Crop Science, 195(6): 420-426.

Jatoi W A, Baloch M J, Kumbhar M B, et al. 2011. Effect of water stress on physiological and yield parameters at anthesis stage in elite spring wheat cultivars. Sarhad Journal of Agriculture, 27: 59-65.

Julkunen-Tiitto R. 1985. Phenolic constituents in the leaves of north willows: methods for the analysis of certain phenolics. Journal of Agricultural and Food Chemistry, 33(2): 213-217.

Khan M A, Shirazi M U, Khan M A, et al. 2009. Role of proline, K/Na ratio and chlorophyll content in salt tolerance of wheat (Triticum aestivum L.). Pakistan Journal of Botany, 41(2): 633-638.

Kumar R R, Karajol K, Naik G R. 2011. Effect of polyethylene glycol induced water stress on physiological and biochemical responses in pigeon pea (Cajanus cajan L. Mill sp.). Recent Research in Science \& Technology, 3: 148-152.

Lum M S, Hanafi M M, Rafii Y M, et al. 2014. Effect of drought stress on growth, proline and antioxidant enzyme activities of upland rice. Journal of Animal and Plant Sciences, 24(5): 1487-1493.

Ma Q Q, Wang W, Li Y H, et al. 2006. Alleviation of photoinhibition in drought-stressed wheat (Triticum aestivum L.) by foliar-applied glycinebetaine. Journal of Plant Physiology, 163(2): 165-175.

Ma X L, Wang Y J, Xie S L, et al. 2007. Glycinebetaine application ameliorates negative effects of drought stress in tobacco. Russian Journal of Plant Physiology, 54: 472-479.

Mafakheri A, Siosemardeh A, Bahramnejad B, et al. 2010. Effect of drought stress on yield, proline and chlorophyll contents in three chickpea cultivars. Australian Journal of Crop Science, 4(8): 580-585.

Mahmood T, Ashraf M, Shahbaz M. 2009. Does exogenous application of glycinebetaine as a pre-sowing seed treatment improve growth and regulate some key physiological attributes in wheat plants grown under water deficit conditions? Pakistan Journal of Botany, 41(3): 1291-1302.

Makbul S, Coskuncelebi K, Turkmen Z, et al. 2006. Morphology and anatomy of Scrophularia L. (Scrophulariaceae) taxa from NE anatolia. Acta Biologica Cracoviensia Series Botanica, 48(1): 33-43.

Makbul S, Türkmen Z, Coskuncelebi K, et al. 2008. Anatomical and pollen characters in the genus Epilobium L. (Onagraceae) from northeast anatolia. Acta Biologica Cracoviensia Series Botanica, 50(1): 51-62.

Makbul S, Guler N S, Durmus N, et al. 2011. Changes in anatomical and physiological parameters of soybean under drought stress. Turkish Journal of Botany, 35: 369-377. 
Mukherjee S P, Chouduri M A. 1983. Implications of water stress induced changes in the levels of endogenous ascorbic acid and hydrogen peroxide in Vigna seedlings. Physiologia Plantarum, 58(2): 166-170.

Mwenye O J, van Rensburg L, van Biljon A, et al. 2016. The role of proline and root traits on selection for drought-stress tolerance in soybeans: A review. South African Journal of Plant and Soil, 33(4): 245-256.

Nawaz K, Ashraf M. 2010. Exogenous application of glycinebetaine modulates activities of antioxidants in maize plants subjected to salt stress. Journal of Agronomy and Crop Science, 196(1): 28-37.

Nawaz T, Hameed M, Ashraf M, et al. 2013. Modifications in root and stem anatomy for water conservation in some diverse blue panic (Panicum antidotale Retz.) ecotypes under drought stress. Arid Land Research and Management, 27(3): $286-297$.

Nemeskéri E, Sárdi É, Remenyik J, et al. 2010. Study of the defensive mechanism against drought in French bean (Phaseolus vulgaris L.) varieties. Acta Physiologia Plantarum, 32(6): 1125-1134.

Omar A A. 2012. Impact of drought stress on germination and seedling growth parameters of some wheat cultivars. Life Science Journal, 9(1): 590-598.

Ozorgucu B, Gemici Y, Turkan I. 1991. Comparative Plant Anatomy. İzmir: Ege University Faculty of Science Publication No: 129. (in Turkish)

Pratap V, Sharma Y K. 2010. Impact of osmotic stress on seed germination and seedling growth in black gram (Phaseolus mungo). Journal of Environmental Biology, 31(5): 721-726.

Raza M A S, Saleem M F, Khan I H, et al. 2012. Evaluating the drought stress tolerance efficiency of wheat (Triticum aestivum L.) cultivars. Russian Journal of Agricultural and Socio-Economic Science, 12(12): 41-46.

Rezaei M A, Kaviani B, Masouleh A K. 2012. The effect of exogenous glycine betaine on yield of soybean (Glycine max (L.) Merr.) in two contrasting cultivars Pershing and DPX under soil salinity stress. Plant Omics Journal, 5(2): 87-93.

Ruzin S E. 1999. Plant Microtechnique and Microscopy. New York: Oxford University Press, 322.

Sadiq M, Akram N A, Ashraf M. 2017. Foliar applications of alpha-tocopherol improve the composition of fresh pods of Vigna radiata subjected to water deficiency. Turkish Journal of Botany, 41: 244-252.

Saeed N, Maqbool N, Haseeb M, et al. 2016. Morpho-anatomical changes in roots of chickpea (Cicer arietinum L.) under drought stress condition. Journal of Agricultural Science and Technology, 6: 1-9.

Seki M, Kamei A, Yamaguchi-Shinozaki K, et al. 2003. Molecular responses to drought, salinity and frost: common and different paths for plant protection. Current Opinion in Biotechnology, 14(2): 194-199.

Shafiq S, Akram N A, Ashraf M. 2015. Does exogenously-applied trehalose alter oxidative defense system in the edible part of radish (Raphanus sativus L.) under water-deficit conditions? Scientia Horticulturae, 185: 68-75.

Shahbaz M, Masood Y, Ashraf M. 2011. Is foliar-applied glycinebetaine effective in mitigating the adverse effects of drought stress on wheat (Triticum aestivum L.)? Journal of Applied Botany and Food Quality, 84(2): 192-199.

Snedecor G W, Cochran W G. 1980. Statistical Methods (7 $7^{\text {th }}$ ed.). Ames: Iowa State University Press, 97.

Subbarao G V, Wheeler R M, Levine L H, et al. 2001. Glycine betaine accumulation, ionic and water relations of red-beet at contrasting levels of sodium supply. Journal of Plant Physiology, 158(6): 767-776.

Vasellati V, Oesterheld M, Medan D, et al. 2001. Effects of flooding and drought on the anatomy of Paspalum dilatatum. Annals of Botany, 88(3): 355-360.

Velikova V, Yordanov I, Edreva A. 2000. Oxidative stress and some antioxidant systems in acid rain-treated bean plants: Protective role of exogenous polyamines. Plant Science, 151(1): 59-66.

Wang W, Vinocur B, Altman A. 2003. Plant responses to drought, salinity and extreme temperatures: towards genetic engineering for stress tolerance. Planta, 218(1): 1-14.

Zhang L, Gao M, Hu J, et al. 2012. Modulation role of abscisic acid (ABA) on growth, water relations and glycinebetaine metabolism in two maize (Zea mays L.) cultivars under drought stress. International Journal of Molecular Sciences, 13: 3189-3202. 